\title{
PEMBERDAYAAN REMAJA MELALUI KETERAMPILAN PRODUK HANDMADE SEBAGAI UPAYA MENCEGAH PERNIKAHAN DINI
}

\author{
Masiah \& Siti Rabiatul Adawiyah \\ IKIP Mataram \\ masiah@ikipmataram.ac.id
}

\begin{abstract}
Abstrak: Provinsi Nusa Tenggara Barat merupakan daerah dengan angka pernikahan dini tertinggi kedua di Indonesia. Menikah dan kemudian hamil di usia dini akan mengancam keselamatan ibu dan bayi karena ketidaksiapan sang ibu dari segala sisi. Persoalan ini akan mempengaruhi IPM NTB karena angka kematian ibu dan bayi adalah salah satu indikatornya. Melihat persoalan tersebut maka perlu perhatian semua kalangan untuk menemukan alternatif terbaik dalam penyelesaian masalah tersebut. Salah satu yang bisa dilakukan adalah dengan memberikan kesibukan 'positif' berupa pelatihan keterampilan produk handmade. Produk handmade berupa tas dari talikur. Tujuan khusus program KKN-PPM ini adalah membekali remaja dengan aktivitas positif dalam mengisi waktu luang sehingga dengan demikian para remaja tidak punya waktu yang terbuang sia-sia apalagi hanya untuk melakukan hal-hal yang tidak mendukung pendidikan dan masa depan mereka. Selain itu tujuan jangka panjangnya adalah para remaja menjadi punya wadah untuk berwirausaha. Pogram KKN-PPM ini telah dilaksanakan pada bulan Juli sampai Agustus 2018. Pelaksanaan program KKN-PPM ini melibatkan mahasiswa dan remaja putri di desa Mambalan Kecamatan Gunungsari Lombok Barat. Adapun tahapan-tahapan kegiatan yang dilakukan meliputi rekrutmen mahasiswa KKN PPM, pembekalan materi, pendampingan dan praktik membuat tas talikur, survey dan koordinasi dengan mitra, sosialisasi program kepada masyarakat, sosialisasi tentang pernikahan dini kepada remaja, sosialisasi tentang produk handmade kepada remaja, pelatihan keterampilan produk handmade oleh mahasiswa KKN-PPM, sosialisasi manajemen pemasaran produk handmade dan evaluasi program. Pada tahap rekrutmen mahasiswa KKN PPM telah dilakukan melalui proses seleksi dengan memenuhi persyaratan akademik dan administratif. Hasil dari pelaksanaan program KKN-PPM ini antara lain; (1) terarahnya pandangan remaja dan masyarakat tentang pernikahan ideal, (2) remaja desa Mambalan mempunyai bekal keterampilan untuk berwirausaha (3) terciptanya produk handmade berupa tas talikur, (4) terciptanya pemahaman remaja tentang manajemen pemasaran produk. Hasil evaluasi program KKN-PPM menunjukkan bahwa kegiatan pemberdayaan remaja melalui keterampilan produk handmade dapat diterima dan sangat bermanfaat untuk meminimalisir terjadinya pernikahan dini.
\end{abstract}

Kata kunci: remaja putri, handmade, pernikahan dini

\begin{abstract}
West Nusa Tenggara Province is the region with the second highest rate of early marriage in Indonesia. Getting married and then getting pregnant at an early age will threaten the safety of the mother and baby because of the unpreparedness of the mother from all sides. This issue will affect the NTB IPM because maternal and infant mortality is one of the indicators. Seeing this problem, it is necessary to pay attention to all groups to find the best alternative in solving the problem. One of the alternatives that can be done is to provide a 'positive' activity in the form of handmade product skills training. Handmade products in the form of bags from talikur. The specific aim of this community program is to equip teenagers with positive activities in filling their spare time so that teenagers do not have the time wasted especially just to do things that do not support their education and future. In addition, the long-term goal is for teenagers to have a place for entrepreneurship. The program was held from July to August 2018. It involved students and young women in the village of Mambalan, Gunungsari District, West Lombok. The stages of the activities carried out included the recruitment of the participants, debriefing materials, mentoring and practice of making talikur bags, surveys and coordination with partners, socialization of the program to the community, socialization of early marriage to teenagers, socialization of handmade products to teenagers, skills training handmade products by participants, socialization of handmade product marketing management and program evaluation. At the stage of participants recruitment, the participants should meet academic and administrative requirements. The results of program include; (1) the direction of
\end{abstract}


adolescents and society about ideal marriage, (2) teenagers in Mambalan village have the skills to entrepreneurship (3) the creation of handmade products in the form of talikur bags, (4) the creation of adolescent understanding of product marketing management. The results of evaluation show that youth empowerment activities through handmade product skills are acceptable and very useful to minimize the occurrence of early marriage.

Keyword: young women, handmade, early marriage

\section{Pendahuluan}

Kasus pernikahan usia dini menjadi perhatian Badan Kependudukan dan Keluarga Berencana Nasional (BKKBN) NTB. Tahun 2016 tercatat sekitar 5\% pernikahan dini terjadi di wilayah NTB, Kepala BKKBN NTB Lalu Makripuddin menjelaskan, angka pernikahan usia dini di NTB cukup tinggi se Indonesia. Bahkan NTB nomor dua setelah Jawa Barat, hal ini sangat memprihatinkan karena akan mengancam keselamatan ibu dan bayinya (lombokpost.net/2016/).

Pernikahan dini masih banyak dijumpai hingga sekarang. Sampai saat ini, masih sering kita dengar fenomena pernikahan dini tidak hanya di kalangan masyarakat adat saja akan tetapi telah merambah pelajar sekolah yang semestinya fokus menuntut ilmu dan mengembangkan bakat. Hal demikian pula yang terjadi di desa Mambalan Kecamatan Gunung Sari Lombok Barat. Undang-undang Perkawinan No 1 tahun 1974 memperbolehkan seorang perempuan usia 16 tahun dapat menikah, sedangkan Undang-undang Kesehatan No 36 Tahun 2009 memberikan batasan 20 tahun karena hubungan sexual yang dilakukan pada usia dibawah 20 tahun beresiko terjadi kanker serviks dan penyakit menular sexual.

Usia remaja menimbulkan berbagai masalah dari berbagai sisi seperti masa remaja yang ingin selalu mencoba-coba sesuatu yang menantang adrenalin, walaupun kadang mereka kurang mengetahui dampak akibat perbuatan tersebut dapat mempengaruhi masa depan mereka. Secara biologis pada masa remaja terjadi proses awal kematangan organ reproduksi manusia, dampaknya apabila di usia remaja ini terjadi kehamilan maka akan banyak resiko kesehatan yang akan dihadapi seperti abortus, anemia, kurang gizi, preeklamsi dan eklamsi. Sedangkan pada saat persalinan dapat menimbulkan, persalinan lama, ketuban pecah dini, ketidakseimbangan kepala bayi dengan lebar panggul, persalinan premature, berat badan bayi lahir rendah dan perdarahan yang dapat mengancam keselamatan jiwa ibu maupun bayinya (Manuaba,2009).

Banyak faktor yang menyebabkan terjadinya pernikahan dini khusunya di desa Mambalan, salah satunya adalah para remaja putri tidak mempunyai kegiatan-kegiatan positif yang mendukung pendidikan dan masa depannya, mereka lebih banyak di sibukkan dengan bermain gadget dan chatting dengan lawan jenis, hal tersebut seakan menjadi media yang paling berperan terjadinya pernikahan dini. Selain itu juga tidak terlepas dari praktik 'kawin lari' yang dikenal dengan merariq dalam terminology suku sasak.

Menurut Reni Kartikawati dalam seminarnya di Universitas Indonesia, Jumat (30/9/2016) tingginya angka pernikahan dini di NTB disebabkan juga karena masyarakat tidak benar-benar memahami tradisi budaya perkawinan, adanya stigma sosial tentang perempuan 
yang tidak menikah muda, adanya kesenjangan konsep 'kedewasaan' antara hukum nasional dengan konsep di hukum adat Suku Sasak (netralnews.com/ ).

Persoalan-persoalan tersebut membuat kami merasa sangat perlu untuk mengadakan pemberdayaan melalui keterampilan produk handmade kepada remaja (khususnya remaja putri) di Desa Mambalan sebagai upaya mencegah pernikahan dini. Keterampilan produk handmade yang dimaksud adalah suatu produk yang dihasilkan oleh tangan manusia tanpa bantuan alat atau mesin. Dengan kegiatan-kegiatan tersebut, kami yakin para remaja akan mempunyai kesibukan positif di luar waktu sekolah karena produk handmade membutuhkan ketelitian dan kreativitas yang tinggi bagi yang menggelutinya. Kegiatan ini sekaligus dapat mendukung program ekonomi kreatif yang saat ini sangat digalakkan oleh pemerintah, selain itu juga dapat menjadi bekal bagi para remaja untuk mengembangkan diri menjadi pengusaha.

Lembaga yang akan menjadi mitra program KKN-PPM adalah Pemerintah Desa Mambalan, Kecamatan Gunung Sari Kabupaten Lombok Barat, Prop. Nusa Tenggara Barat. Pemerintah dan aparat setempat akan bersama-sama merencanakan dan melaksanakan program KKN-PPM untuk nantinya dapat menjadi model percontohan penanganan problem serupa untuk desa-desa di sekitarnya. Salah satu pertimbangan memilih Desa Mambalan adalah karena secara geografis Desa Mambalan tidak terlalu jauh dari kota Mataram, kondisi tersebut seharusnya tidak akan bermasalah dengan pernikahan dini karena umumnya pernikahan dini sering terjadidi daerahdaerah yang jauh dari pusat kota danterpencil akan tetapi kenyataannya tidak demikian.

Rendahnya angka pendidikan lulusan dari SLTP sampai Sarjana salah satu penyebabnya adalah pernikahan dini, karena ketika pernikahan sudah terjadi maka pendidikan formalnya otomatis akan terhenti. Bahkan ketika sudah duduk di bangku kuliahpun, ketika pada saat itu terjadi pernikahan maka pendidikannya terhenti apalagi jika pernikahan terjadi pada usia sekolah. Inilah kondisi yang sangat memprihatinkan yang harus segera ditindaklanjuti penangannya.

Kelompok sasaran program KKN-PPM adalah remaja/masyarakat di 4 Dusun yaitu Dusun Mambalan, Buwuh, Lilir Barat dan Batu Riti. Berikut penjelasan kelompok sasaran program KKNPPM.

1. Kelompok masyarakat (para orang tua)

Para orang tua memiliki peranan penting dalam menangani pernikahan dini, Karena kebanyakan para orang tua di pedesaan tidak memahami kondisi anak yangsiap untuk dinikahkan. Kelompok orang tua, terutama yang memiliki anak gadis akan menjadi prioritas sasaran kegiatan ini. Dalam hal ini kami ingin mengubah paradigma dan pola pikir mereka tentang pernikahan melalui sosialisasi dan FGD. Diharapkan dari kegiatan ini masyarakat memahami dampak negatif dari pernikahan dini sehingga dapat dijadikan pertimbangan jika hendak menikahkan anak-anak mereka. Selain itu juga diharapkan agar masyarakat memahami hakekat pernikahan yang ideal sehingga akan melahirkan generasi-generasi emas dimasa depan.

2. Perangkat Desa

Perangkat desa dijadikan sebagai salah satu sasaran adalah karena pemerintah desa menjadi lembaga yang paling dekat dan mempunyai wewenang untuk mengatur mengatur 
masyarakatnya kearah yang lebih positif.

3. Kelompok Remaja

Kelompok Remaja di Desa Mambalan menjadi kelompok sasaran utama dari program KKNPPM ini. Di sini, remaja akan diberikan pengetahuan tentang pernikahan yang ideal atau kondisi-kondisi yang dianggap sudah siap untuk menikah. Dan yang paling penting untuk kelompok sasaran ini adalah akan diberikan keterampilan berupa keterampilan produk handmade sebagai upaya untuk mencegah pernikahan dini.

\section{Metode}

Kegiatan pengabdian ini dilakukan dengan melalui 2 tahap yaitu tahap persiapan dan pembekalan dan tahap pelaksanaan. Penjelasan masing-masing tahap adalah sebagai berikut.

\section{Persiapan dan Pembekalan}

Persiapan dan pembekalan program KKN-PPM ini terdiri dari beberapa langkah yaitu; Pembentukan tim pengelola KKN PPM, Survei oleh mahasiswa, Pendataan sasaran oleh tim unit KKN PPM, Orientasi atau pembekalan DPL dan mahasiswa dan Penyusunan program kerja.

\section{Pelaksanaan KKN PPM}

Pelaksanaan seluruh program ini diorganisir oleh tim KKN-PPM IKIP Mataram. Beberapa tindakan operasional yang dilakukan berupa kegiatan utama dalam mencapai target program KKN-PPM dapat dilihat dalam diagram 1. Sasaran utama kegiatan adalah peran aktif remaja dalam setiap pelaksanaan kegiatan sehingga pemberdayaan remaja melalui keterampilan handmade sebagai upaya mencegah pernikahan dini dapat terwujud dengan maksimal. Berikut dijelaskan masing-masing kegiatan program KKN-PPM.

1. Inisiasi program

Kegiatan ini meliputi perkenalan antara mahasiswa KKN dengan masyarakat sekitar, sosialisasi tujuan dan diskusi program, brainstorming, dan asesmen mengenai kondisi desa. Kegiatan ini awal ini bertujuan agar masyarakat desa merasa memiliki dan bertanggung jawab terhadap program yang ingin dicapai bersama dengan asumsi mereka memiliki kesempatan untuk menuangkan ide-ide dalam diskusi, bukan sekedar menjalankan apa yang telah mahasiswa KKN-PPM rencanakan.

2. Pembentukan struktur organisasi

Kegiatan ini berupa pembentukan struktur organisasi yang meliputi mahasiswa KKN-PPM dan remaja selaku peserta program, sehingga program-program yang dapat dilaksanakan secara teratur dan sistematis.

3. Sosialisasi kepada masyrakat (orang tua) akan dampak pernikahan dini Kegiatan ini bertujuan untuk mengubah pola pikir dan paradigma para orang tua tentang sebuah pernikahan. Hal ini dilakukan karena sebagian besar orang tua di pedesaan tidak memperdulikan umur anaknya ketika menikah, apalagi jika ada laki-laki yang dianggap mapan secara financial melamar anak gadisnya maka tanpa pikir panjang, bahkan tanpa persetujuan anaknya akan segera dinikahkan. Setelah kegiatan ini diharapkan tingginya kesadaran para orang tua untuk melihat dari segala sisi sebelum menikahkan anak mereka. 


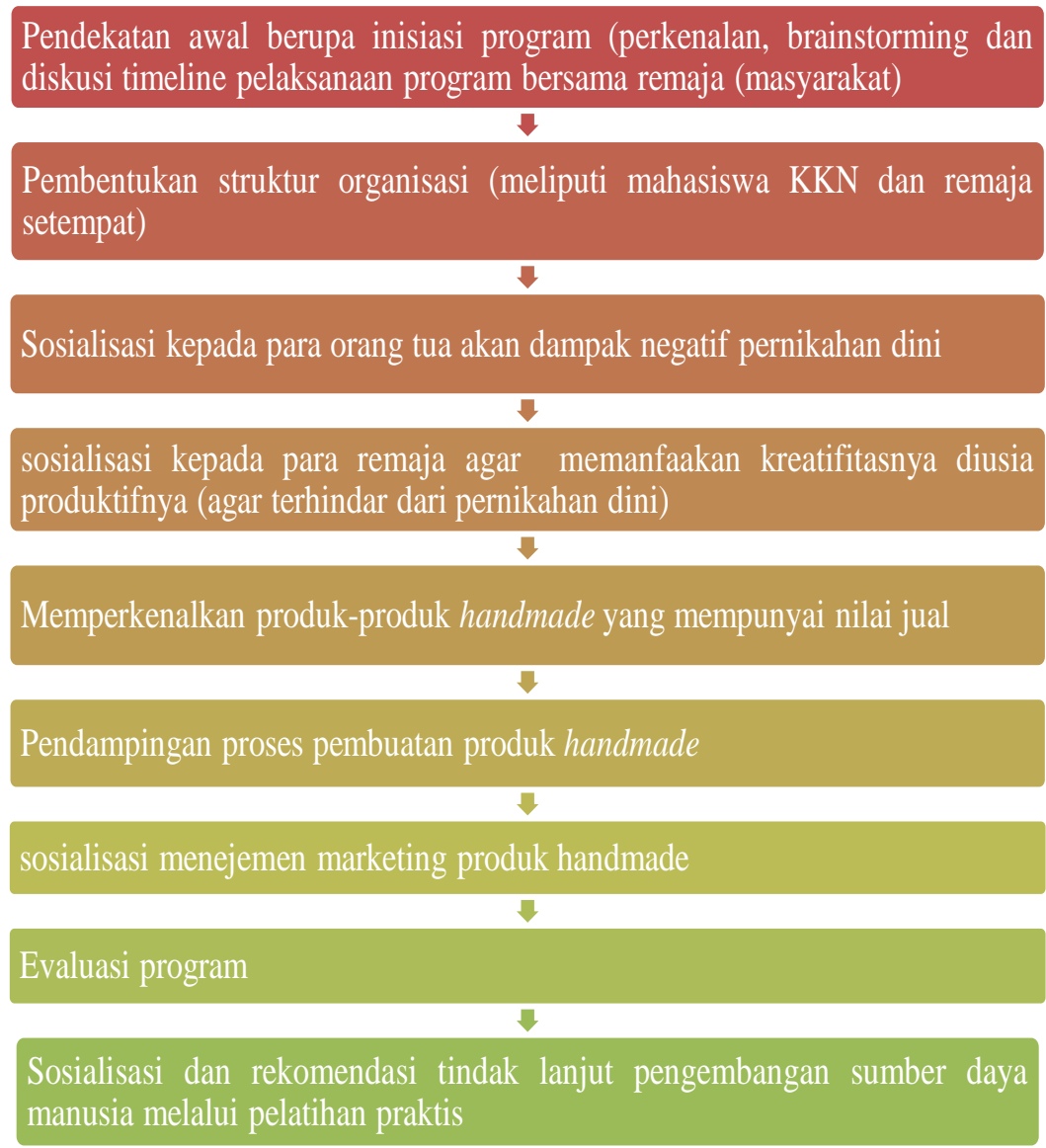

Diagram 1. Langkah kegiatan Program KKN-PPM

4. Sosialisasi kepada remaja terkait pernikahan dini dan motivasi untuk produktif diusianya Kegiatan ini diharapkan agar para remaja mempunyai kepedulian yang tinggi terhadap diri mereka saat ini dan di masa depan. Hal yang paling penting untuk diperhatikan bahwa, menikah di usia dini menimbulkan banyak kekwatiran baik dari segi kesehatan ibu dan anak, mental, maupun psikologinya. Sebaliknya, usia muda adalah usia yang cocok untuk memacu kreatifitas dan produktif dalam hal yang sifatnya positif.

5. Memperkenalkan produk handmade

Kegiatan ini bertujuan untuk memperkenalkan produk-produk handmade yang bisa dipelajari dan dikembangkan.

6. Sosialisasi menejemen pemasaran produk handmade

Produk handmade yang sudah jadi (siap pakai) selanjutnya akan dijual/dipasarkan agar bermanfaat bagi remaja peserta program KKN-PPM. Kegiatan ini bertujuan agar para remaja peserta program KKN-PPM tahu bagaimana cara memasarkan produk dan bagaimana cara membaca pasar. Kegiatan sangat penting karena menyangkut eksistensi produk kreatif yang dihasilkan, bukan saja selama berlangsungnya program KKN-PPM namun sampai kedepannya bahkan diharapkan agar keterampilan ini terus dikembangkan sehingga mereka bisa mandiri secara finansial.

7. Evaluasi program 
Evaluasi program bertujuan untuk mengetahui keterlaksanaan dan efektivitas program yang sedang dan telah dilaksanakan.

\section{Hasil dan Pembahasan}

Kegiatan KKN PPM ini telah dilaksanakan di desa Mambalan kecamatan Gunungsari Kabupaten Lombok Barat NTB. Desa Mambalan terdiri dari 4 dusun meliputi; Dusun Mambalan, Buwuh, Lilir Barat dan Batu Riti. Kegiatan ini dimulai sejak bulan Juli sampai Agustus 2018. Berikut rincian kegiatan yang telah dilaksanakan.

\section{Persiapan dan Pembekalan}

Persiapan dimulai dengan memberikan pembekalan oleh tim dosen KKN PPM kepada mahasiswa tentang program-program yang akan dilaksanakan, pembekalan berisi materi tentang bagaimana melatihkan keterampilan handmade kepada remaja serta praktek langsung membuat produk handmade yaitu tas talikur. Selanjutnya mahasiswa melakukan survey dan pendataan lokasi sasaran yaitu di desa Mambalan untuk memperoleh informasi terkini tentang keadaan desa.
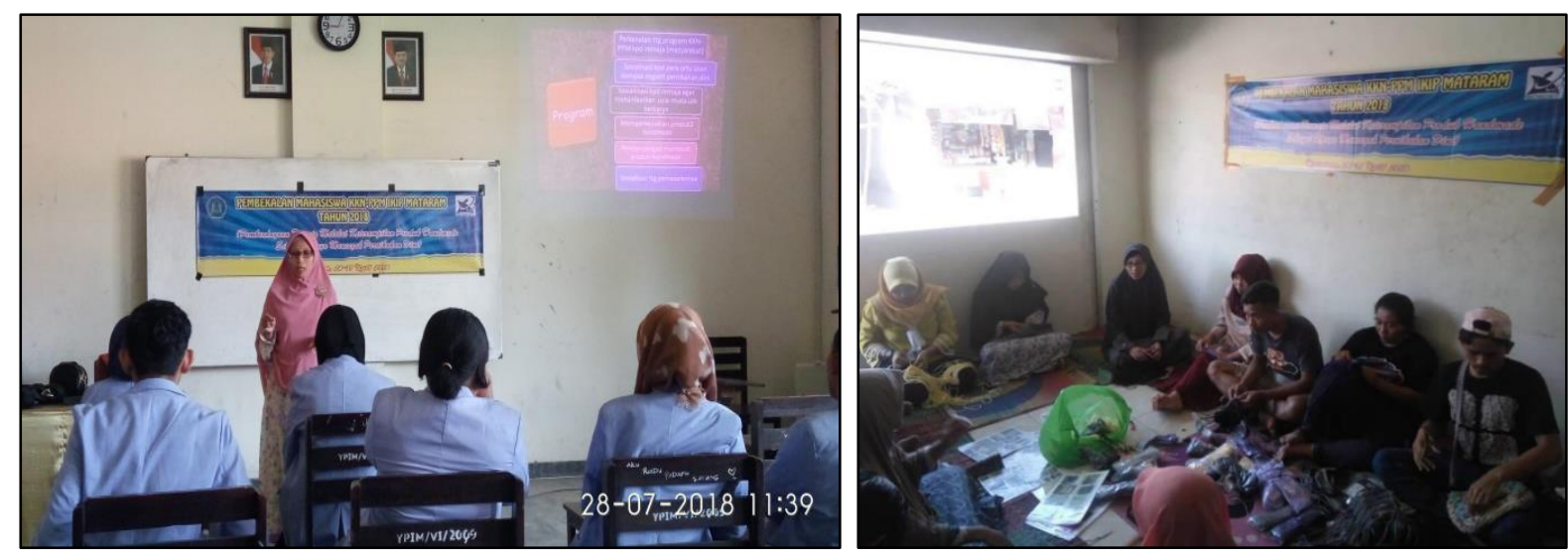

Gambar 1. Pembekalan materi dan paraktek kepada mahasiswa KKN PPM

\section{Pelaksanaan KKN PPM}

Kegiatan KKN PPM dimulai dengan perkenalan antara mahasiswa KKN PPM dengan masyarakat Desa Mambalan, selanjutnya dibentuk struktur organisasi yang meliputi mahasiswa KKN-PPM dan remaja. Kegiatan berikutnya adalah memberikan sosialisasi kepada masyarakat (orang tua) akan dampak pernikahan dini. Melalui sosialisasi ini terlihat bahwa selama ini masyarakat tidak begitu mempertimbangkan usia anak ketika akan dinikahkan, namun setelah mengikuti kegiatan sosialisasi para orang tua menjadi lebih respect terhadap segala hal yang berhubungan dengan pernikahan. Hal tersebut mengindikasikan bahwa kegiatan ini memberikan dampak positif terhadap pandangan masyarakat terhadap pernikahan ideal.

Selain memberikan sosialisasi kepada para orang tua, mahasiswa KKN PPM juga memberikan sosialisasi kepada remaja terkait pernikahan dini dan memberikan motivasi untuk produktif diusianya. Dalam sosialisasi ini juga diperkenalkan produk-produk handmade yang bisa menjadi pilihan remaja dalam mengisi waktu luang mereka. Setelah sosialisasi selanjutnya mahasiswa KKN PPM memberikan pelatihan membuat tas talikur. 

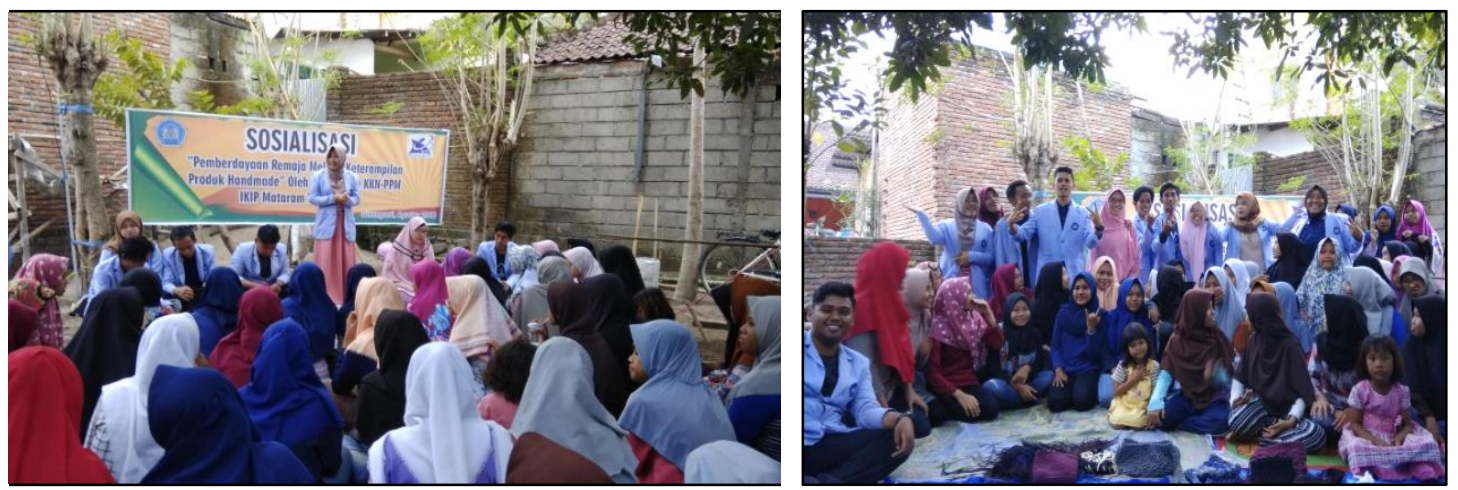

Gambar 2. Kegiatan sosialisasi kepada remaja desa Mambalan

Pelatihan membuat tas talikur diikuti oleh kurang lebih 40 orang remaja yang terdiri dari anak SLTP/Sederajat dan SLTA/Sederajat. Perekrutan peserta pelatihan berdasarkan tujuan utama program KKN PPM yaitu agar kegiatan ini dapat mencegah pernikahan dini, atas dasar demikanlah peserta yang boleh mengikuti pelatihan diprioritaskan bagi mereka yang berumur di bawah 16 tahun. Waktu pelatihan mengikuti waktu luang peserta yaitu pada sore hari dan hari libur sekolah. Dalam setiap pelatihan antusiasme remaja sangat tinggi, hal ini dapat dilihat dari keikutsertaan mereka yang hampir tidak pernah absen.
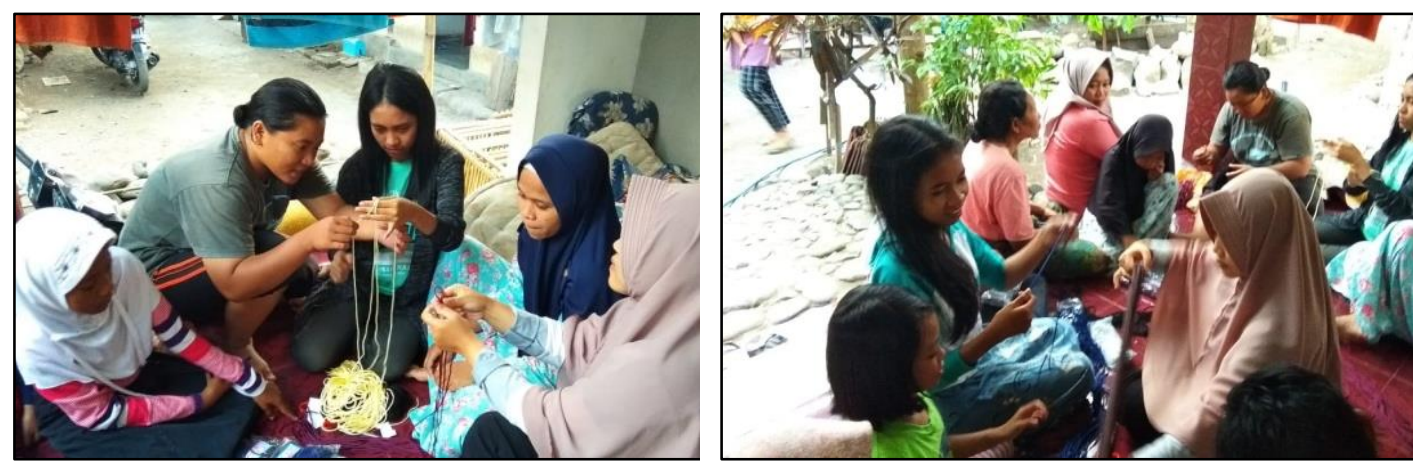

Gambar 3. Pelatihan remaja oleh mahasiswa KKN PPM dalam membuat tas talikur

Produk tas talikur yang dihasilkan beraneka ragam, mulai dari tas selempengan panjang, pendek hingga tas tangan (handbag) dengan motif yang bermacam-macam sehingga menambah warna produk mereka.

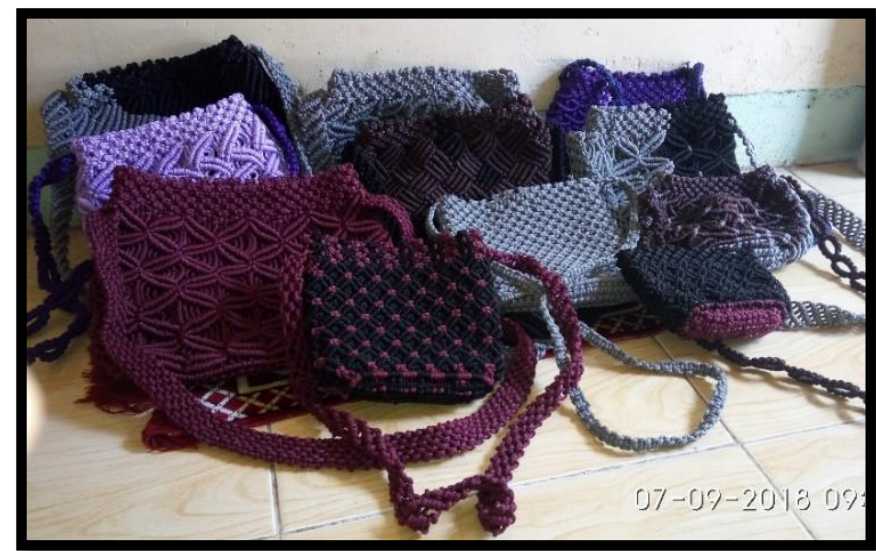

Gambar 4. Beberapa produk handmade dari program KKN-PPM

Selain memberikan pelatihan keterampilan tas talikur, para mahasiswa KKN PPM juga 
membekali para remaja tentang bagaimana memasarkan produk. Sebagaimana yang telah dilaksanakan oleh mahasiswa yang melatihkan kemampuan para remaja dalam menghasilkan produk, bersamaan itu pula telah diberikan pendampingan managemen pemasaran produk. Media pemasaran yang paling efektif untuk saat ini adalah melalui media sosial. Pemasaran melalui media sosial selain sangat efektif juga menjadi pengalihan aktifitas remaja yang sebelumnya dianggap sebagai salah satu media yang memberikan kontribusi terhadap pernikahan dini namun sekarang media tersebut menjadi sangat bermanfaat dalam pemberdayaan mereka.

Evaluasi program bertujuan untuk mengetahui tingkat pencapaian tujuan program KKN PPM. Evaluasi dilakukan pada setiap tahapan kegiatan dengan menggunakan berbagai instrumen, diantaranya; lembar observasi pelaksanaan kegiatan, angket respon peserta pelatihan dan lembar penilaian kinerja. Hasil evaluasi pada setiap program menunjukkan hasil yang sesuai dengan tujuan program. Indicator keberhasilan pencapaian program meliputi (1) partisipasi remaja dalam mengikuti pelatihan (2) dukungan masyarakat sekitar terhadap seluruh rangkaian program sangat besar (3) remaja yang mengikuti pelatihan merasa sangat terbantu atas program KKN PPM mahasiswa IKIP Mataram.

\section{Kesimpulan}

Program KKN PPM yang telah dilaksanakan di desa Mambalan dari bulan Juli-Agustus 2018 dapat dikatakan berhasil dan sesuai dengan tujuan program yang telah direncanakan sebelumnya. Adapun saran yang perlu diperhatikan oleh semua kalangan yaitu perlunya dukungan dari semua pihak terutama keluarga dan pemerintah dalam pencegahan pernikahan dini serta perlunya program KKN PPM lanjutan untuk mengembangkan potensi yang dimiliki para remaja agar lebih produktif diusia mudanya.

\section{Ucapan Terimakasih}

Ucapan terimaksih yang tinggi kepada;

1. Direktorat Riset dan Pengabdian kepada Masyarakat, Direktorat Jenderal Penguatan Riset dan Pengembangan Kementerian Riset, Teknologi, dan Pendidikan Tinggi atas kepercayaannya sehingga program ini dapat didanai.

2. LPPM IKIP Mataram yang tiada henti memberikan arahan dan bimbingan sehingga kegiatan ini dapat terlaksana dengan baik.

\section{Referensi}

http://www.lombokpost.net/2016/05/25/pernikahan-dini-ntb-tinggi/ (online diakses tanggal I juni 2017)

http://www.netralnews.com/news/kesra/read/27165/angka.pernikahan.dini.di.indonesia.tertinggi.k edua.di.asean (online diakses tanggal I juni 2017)

Manuaba, IBG. 2009. Memahami Kesehatan Reproduksi. Arcan. Jakarta.

Tim. 2013. Peraturan Akademik IKIP Mataram, Institut Keguruan dan Ilmu Pendidikan 